\title{
Hybrid effects of zirconia nanoparticles with aluminum borate whiskers on mechanical properties of denture base resin PMMA
}

\author{
Xiu-Yin ZHANG ${ }^{1}$, Xin-Jing ZHANG ${ }^{1}$, Zhuo-Li HUANG ${ }^{1}$, Bang-Shang ZHU² and Rong-Rong CHEN ${ }^{1}$ \\ ${ }^{1}$ Department of Prosthodontics, 9th People's Hospital, Shanghai Jiao Tong University, School of Medicine, Shanghai Key Laboratory of Stomatology, \\ Shanghai 200011, PR China \\ ${ }^{2}$ Instrumental Analysis Center, Shanghai Jiao Tong University, Shanghai 200030, PR China \\ Corresponding author, Xiu-Yin ZHANG; E-mail: xiuyinzhangxyz@163.com
}

\begin{abstract}
The aim of this study was to investigate the hybrid effects of $\mathrm{ZrO}_{2}$ nanoparticles (nano- $\mathrm{ZrO}_{2}$ ) and aluminum borate whiskers (ABWs) on flexural strength and surface hardness of denture base resin, polymethyl methacrylate (PMMA). Both nano- $\mathrm{ZrO}{ }_{2}$ and $\mathrm{ABWs}$ were modified by silane coupling agent (Z6030) before being mixed with PMMA. Various amounts of silanized nano-ZrO $\mathrm{Z}_{2}$ and $\mathrm{ABWs}$ were mixed with PMMA to prepare $\mathrm{ZrO}_{2}$-ABW/PMMA composites. Flexural strength and surface hardness were evaluated using threepoint bending test and Vickers hardness test respectively. Fractured surfaces were also observed by scanning electron microscopy (SEM). The mechanical behaviors of silanized $\mathrm{ZrO}_{2}$-ABW/PMMA composites were significantly improved. Flexural strength reached a maximum value of $108.01 \pm 5.54 \mathrm{MPa}$ when $2 \mathrm{wt} \%$ of nano- $\mathrm{ZrO}_{2}$ was mixed with $\mathrm{ABWs}$ at a $\mathrm{ZrO}_{2} / \mathrm{ABW}$ ratio of $1: 2$, amounting to an increase of $52 \%$ when compared with pure PMMA. Surface hardness achieved a maximum value of $22.50 \pm 0.86 \mathrm{MPa}$ when 3 wt $\%$ of nano- $\mathrm{ZrO}_{2}$ was mixed with $\mathrm{ABW}$ at the same $\mathrm{ZrO}_{2} / \mathrm{ABW}$ ratio, which was an increase of $27 \%$ when compared with pure PMMA.
\end{abstract}

Keywords: Zirconia nanoparticles, Aluminum borate whiskers, PMMA, Flexural strength, Surface hardness

\section{INTRODUCTION}

Polymethyl methacrylate, PMMA, is still widely used as denture base material due to its satisfactory esthetics, easy operation, low cost, and favorable stability in the oral environment ${ }^{1,2}$. However, poor mechanical property is one of the major shortcomings of PMMA denture base composites, which limits their potential use $e^{3,4)}$. To facilitate more clinical uses, various micro- or nanosized fillers have been incorporated into PMMA ${ }^{4 \cdot 77}$. Although this area has seen significant $\operatorname{progress}^{8-10)}$, the fracture of dentures remains an unresolved clinical problem.

Recent reviews of nanocomposites have highlighted filler materials in the form of whiskers or fibers ${ }^{11-14)}$, due to the latter's high mechanical performance ${ }^{15,16)}$. Whiskers are a highly pure and acicular material with a single crystal structure fabricated under well controlled conditions. Their large length-diameter ratio effectively prevents the matrix from crack development, while their highly ordered arrangement of atoms results in low brittleness, thus enhancing the mechanical properties ${ }^{17}$. Among the whisker reinforcement materials, aluminum borate $\left(\mathrm{Al}_{18} \mathrm{~B}_{4} \mathrm{O}_{33}\right)$ whiskers offer superior mechanical properties at a low cost. Our previous study showed that flexural strength, surface hardness, and thermal stability were significantly increased by adding an optimum amount of aluminum borate whiskers (ABWs) to the PMMA matrix ${ }^{18)}$.

Nowadays, numerous investigations have focused on nanomaterials to enhance the mechanical properties of PMMA, because of their special characteristics ${ }^{11-15)}$. In recent years, bioceramic nanoparticles have been used to enhance the mechanical properties of PMMA ${ }^{3,19}$.
$\mathrm{ZrO}_{2}$, being a typical bioceramic, shows great biocompatibility and bioactivity. $\mathrm{ZrO}_{2}$ improves mechanical properties and is suggested to be relatively suitable for dental restorations $\mathrm{s}^{20}$.

Mixing very short fillers of less than $1 \mu \mathrm{m}$ (microfillers) with larger fillers of more than $1 \mu \mathrm{m}$ (macrofillers) has been shown to produce homogenous structures and improve the mechanical properties of PMMA composites. This is because the microfillers prevented the settling of macrofillers when mixing with monomers ${ }^{21}$. Lin $e t a l{ }^{15)}$ found a significant increase in the mechanical properties of polyether ether ketone (PEEK) composites which were reinforced with carbon fibers (microfillers) and $\mathrm{ZrO}_{2}$ nanoparticles (nanofillers). However, research on reinforcing PMMA denture base composites by compounding nanofillers together with microfillers remains scarce. The aim of this study was to evaluate the hybrid effects of PMMA-based composites with different amounts of silanized $\mathrm{ZrO}_{2}$ nanoparticles (nano- $\mathrm{ZrO}_{2}$ ) and $\mathrm{ABWs}$ on flexural strength and surface hardness.

\section{MATERIALS AND METHODS}

\section{Materials}

Type 2 denture base resin powder and liquid were supplied by Second Medical Zhangjiang Biological Material Co., Ltd. (Shanghai, PR China). $\mathrm{ZrO}_{2}$ nanoparticles (Tosoh Corp., Japan) had an average granularity of $90 \mathrm{~nm}$ and an average surface area of $7 \pm 2$ $\mathrm{m}^{2} / \mathrm{g}$. Aluminum borate whiskers (Shanghai Whisker Composites Manufacturing Co., Ltd., Shanghai, PR China) were of 5-30 $\mu \mathrm{m}$ length and a diameter of less than $1.5 \mathrm{~nm}$, with a surface area of $2.0-2.5 \mathrm{~m}^{2} / \mathrm{g}$. Silane 
coupling agent was Z-6030 supplied by Dow Chemical Company (USA).

\section{Methods}

1. Modification of $\mathrm{ZrO}_{2}$ nanoparticles

$1.5 \mathrm{wt} \%$ of Z-6030 was mixed with $10 \mathrm{~g}$ of acetone for $10 \mathrm{~min}$ by ultrasonic oscillation. Nano- $\mathrm{ZrO}_{2}$ particles were dispersed into the mixture at room temperature and mixed again ultrasonically for $30 \mathrm{~min}$. Temperature was raised to $80^{\circ} \mathrm{C}$ for coupling reaction to occur. After nano- $\mathrm{ZrO}_{2}$ was dried for $24 \mathrm{~h}$, silanized $\mathrm{ZrO}_{2}$ nanoparticles were thus obtained.

\section{Modification of aluminum borate whiskers}

Pure ethanol and distilled water were mixed at 9:1 (wt) ratio, and $\mathrm{pH}$ value was adjusted to $4-5$ using glacial acetic acid. Z-6030 of 2 wt\% was added to the mixture and mixed using a magnetic stirring apparatus for 1 $\mathrm{h}$ to pre-hydrolyze Z-6030. Meanwhile, ABWs were ultrasonically mixed with distilled water (ABW/water ratio of $1: 5$ ) for $5 \mathrm{~min}$ to obtain the ABWs solution. Pre-hydrolyzed Z-6030 was slowly added to the ABWs solution and stirred for $10 \mathrm{~min}$. After $30 \mathrm{~min}$, the mixture was filtered by vacuum filtration at room temperature. Coupling reaction continued to occur in the remaining slurry. After drying at $120^{\circ} \mathrm{C}$ for $24 \mathrm{~h}$, silanized aluminum borate whiskers were thus obtained.

\section{Preparation of standardized specimens}

Silanized nano- $\mathrm{ZrO}_{2}$ and $\mathrm{ABW}$ were ball-milled with PMMA powder at a speed of $180 \mathrm{rev} / \mathrm{min}$ for $10 \mathrm{~min}$ every other alternate way to run the mixed powder for dry grinding for 120 min using a ball mill apparatus (XQM, PR China). Mixed powder was dispersed in mono-MMA liquid at a powder/liquid mass ratio of 2:1. Polymerization of denture base resin was initiated, and silanized $\mathrm{ZrO}_{2}-\mathrm{ABW} / \mathrm{PMMA}$ nanocomposites were thus obtained.

The nanocomposites were divided into four groups according to different amounts of nano- $\mathrm{ZrO}_{2}$ at $1,2,3$, and $4 \mathrm{wt} \%$. Each group was subdivided according to $\mathrm{ZrO}_{2} / \mathrm{ABW}$ mass ratios of $2: 1,1: 1,1: 2$, and $1: 3$. Unsilanized $\mathrm{ZrO}_{2}$-ABW/PMMA nanocomposites were prepared in the same way by admixing unsilanized nano- $\mathrm{ZrO}_{2}$ and $\mathrm{ABWs}$, and were regarded as the control groups. Pure PMMA was used as the blank group.

Based on the recommendations of ISO 20795$1: 2008$, all specimens in this study had the standardized dimensions of $64 \mathrm{~mm}$ length, $10.0 \pm 0.2 \mathrm{~mm}$ width, and $3.3 \pm 0.2 \mathrm{~mm}$ height ${ }^{22}$. Six standardized specimens were used in each group.

\section{Vickers hardness test}

One specimen, randomly chosen from each group, was polished by waterproof abrasive paper (240 to $2000 \mathrm{CW}$ ) to mirror-like smoothness. Six points were randomly selected from each mirror-polished specimen to be subjected to Vickers hardness testing using a microhardness tester (HX-1000TM, Shanghai Taiming Optical Instruments Co., Ltd., PR China). Loading was
$50 \mathrm{gf}(0.490 \mathrm{~N})$ at a speed of $0.05 \mathrm{~mm} / \mathrm{s}$ for $10 \mathrm{~s}$.

\section{Three-point bending test}

Three-point bending test, according to ISO 1566:19993), was carried out on all groups in a constant-temperature water bath of $37^{\circ} \mathrm{C}$ for $48 \pm 2 \mathrm{~h}$. Using a universal testing machine (EZ20, Lloyd Instruments Ltd., UK), loading was carried out on each test specimen with a span of 50 $\mathrm{mm}$ and at a crosshead speed of $5 \mathrm{~mm} / \mathrm{min}$ until fracture occurred.

6. Scanning electron microscope (SEM) observation One specimen was randomly selected from each group. Fractured surface was coated with gold and observed by field emission scanning electron microscopy (Sirion 200, FEI Co., USA).

7. Statistical analysis

Data were analyzed using three-level nested ANOVA by SAS 6.12 statistical software (SAS Institute Inc., USA).

\section{RESULTS}

\section{Flexural strength}

Flexural strength was significantly reinforced by nano$\mathrm{ZrO}_{2}$ and $\mathrm{ABW}$, and silanized $\mathrm{ZrO}_{2}-\mathrm{ABW} / \mathrm{PMMA}$ nanocomposites exhibited apparently higher flexural strength than the unsilanized composites (control groups) (Table 1). With an increase in the amount of fillers, the flexural strength of silanized $\mathrm{ZrO}_{2}-\mathrm{ABW} /$ PMMA nanocomposites increased when the amount of nano- $\mathrm{ZrO}_{2}$ was increased from $1 \%$ to $2 \%$, but decreased when it was increased from $2 \%$ to $4 \%$ (Fig. 1). Flexural strength achieved the highest value when $2 \%$ of nano$\mathrm{ZrO}_{2}$ was added, and which was significantly different from the other groups $(p<0.001)$.

The $\mathrm{ZrO}_{2} / \mathrm{ABW}$ ratio also played an important role in reinforcing the composites. Flexural strength showed an increase at first, followed by a decrease, with an increase in $\mathrm{ZrO}_{2} / \mathrm{ABW}$ ratio (i.e., amount of $\mathrm{ABWs}$ increased while the amount of nano- $\mathrm{ZrO}_{2}$ remained constant) (Fig. 1). At nano- $\mathrm{ZrO}_{2}$ of $2 \%$, flexural strength achieved the maximum value of $108.01 \pm 5.54 \mathrm{MPa}$ with $\mathrm{ZrO}_{2} / \mathrm{ABW}$ ratio of $1: 2$, an increase of $52 \%$ when compared with the blank group (70.88 $\pm 7.73 \mathrm{MPa})$. It was significantly different from the other groups at the same nano- $\mathrm{ZrO}_{2}$ amount $(p<0.05)$ and from the control group $(p<0.01)$

\section{SEM observation}

The morphology of fractured surfaces of different groups was observed by SEM. Figure 2 shows the representative photographs of $\mathrm{ZrO}_{2} / \mathrm{ABW}$ ratios of $2: 1$, $1: 1,1: 2,1: 3$ at $\mathrm{ZrO}_{2}$ amount of $2 \%$ and $\mathrm{ZrO}_{2} / \mathrm{ABW}$ ratio of $1: 3$ at $\mathrm{ZrO}_{2}$ amount of $4 \%$. At $\mathrm{ZrO}_{2} / \mathrm{ABW}$ ratio of $2: 1$, the fracture surface was relatively smooth (Fig. 2(a1)). At a higher magnification, it could be seen that nano$\mathrm{ZrO}_{2}$ dispersed evenly in the matrix, while ABWs were not found since its amount was low (Fig. 2(a2)). At $\mathrm{ZrO}_{2} / \mathrm{ABW}$ ratio of $1: 1$, ABWs could be found at lower 
Table 1 Flexural strength of each group (The values with the same mark have no significant difference)

\begin{tabular}{cccc}
\hline \multicolumn{3}{c}{ Flexural strength $(\mathrm{MPa})$} \\
\hline \multirow{3}{*}{$\mathrm{ZrO}_{2}$} & $\mathrm{ZrO}_{2} / \mathrm{ABW}$ & $\begin{array}{c}\text { Experimental } \\
\text { group }\end{array}$ & Control group \\
& & $77.9 \pm 5.1^{\mathrm{a}}$ & $77.5 \pm 2.7^{\mathrm{a}}$ \\
& $2: 1$ & $81.6 \pm 7.2^{\mathrm{a}}$ & $81.3 \pm 5.0^{\mathrm{a}}$ \\
$1 \%$ & $1: 1$ & $90.1 \pm 3.1^{\mathrm{a}}$ & $84.5 \pm 3.4^{\mathrm{a}}$ \\
& $1: 2$ & $86.9 \pm 6.3^{\mathrm{a}}$ & $83.9 \pm 4.8^{\mathrm{a}}$ \\
& $1: 3$ & $92.1 \pm 4.5^{\mathrm{a}}$ & $78.5 \pm 3.1^{\mathrm{a}}$ \\
& $2: 1$ & $96.2 \pm 4.9^{\mathrm{b}}$ & $84.8 \pm 6.8^{\mathrm{a}}$ \\
$2 \%$ & $1: 1$ & $108.0 \pm 5.5^{\mathrm{c}}$ & $81.3 \pm 5.8^{\mathrm{a}}$ \\
& $1: 2$ & $97.1 \pm 3.6^{\mathrm{b}}$ & $81.4 \pm 7.6^{\mathrm{a}}$ \\
& $1: 3$ & $82.6 \pm 7.2^{\mathrm{a}}$ & $74.2 \pm 3.6$ \\
& $2: 1$ & $86.6 \pm 4.8^{\mathrm{a}}$ & $75.7 \pm 6.4$ \\
$3 \%$ & $1: 1$ & $82.5 \pm 5.4^{\mathrm{a}}$ & $74.1 \pm 4.2$ \\
& $1: 2$ & $82.3 \pm 6.4^{\mathrm{a}}$ & $81.4 \pm 6.9^{\mathrm{a}}$ \\
& $1: 3$ & $73.1 \pm 4.2$ & $68.5 \pm 3.7$ \\
& $2: 1$ & $78.3 \pm 4.8^{\mathrm{a}}$ & $76.7 \pm 5.9^{\mathrm{a}}$ \\
& $1: 1$ & $77.2 \pm 4.6^{\mathrm{a}}$ & $73.3 \pm 7.7$ \\
& $1: 2$ & $73.3 \pm 5.8$ & $73.4 \pm 6.4$ \\
\hline
\end{tabular}

Blank group

(pure PMMA)

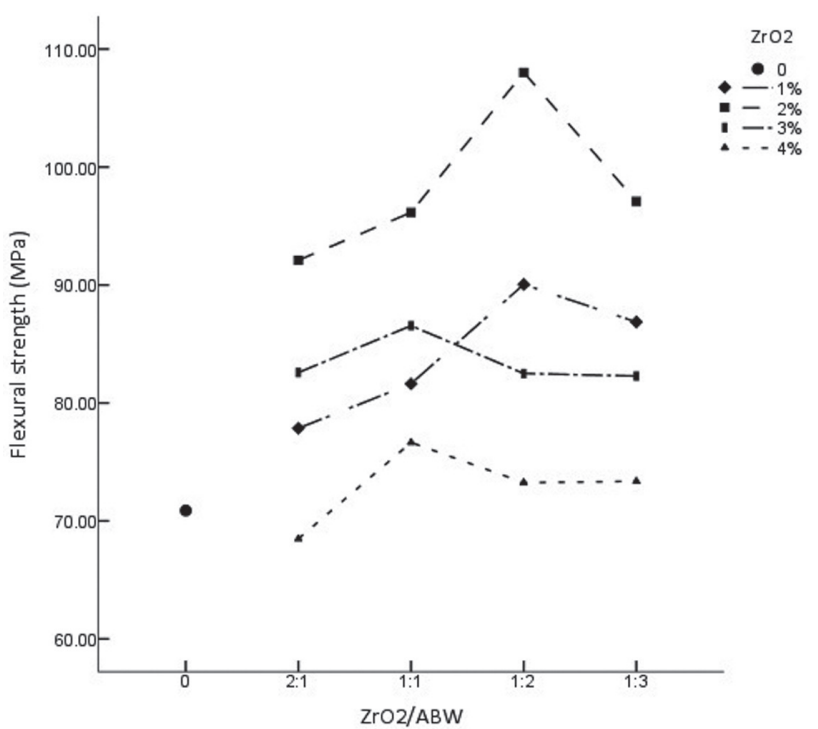

Fig. 1 Flexural strengths of silanized $\mathrm{ZrO}_{2}$-ABW/PMMA nanocomposites.

magnification and the fracture surface was irregular (Fig. 2(b1)). The ABWs blended well with the resin matrix, and fracture fossa was found at higher magnification (Fig. 2(b2)). As the amount of ABWs increased, more and more whiskers were seen to be well dispersed in the matrix at lower magnification, with

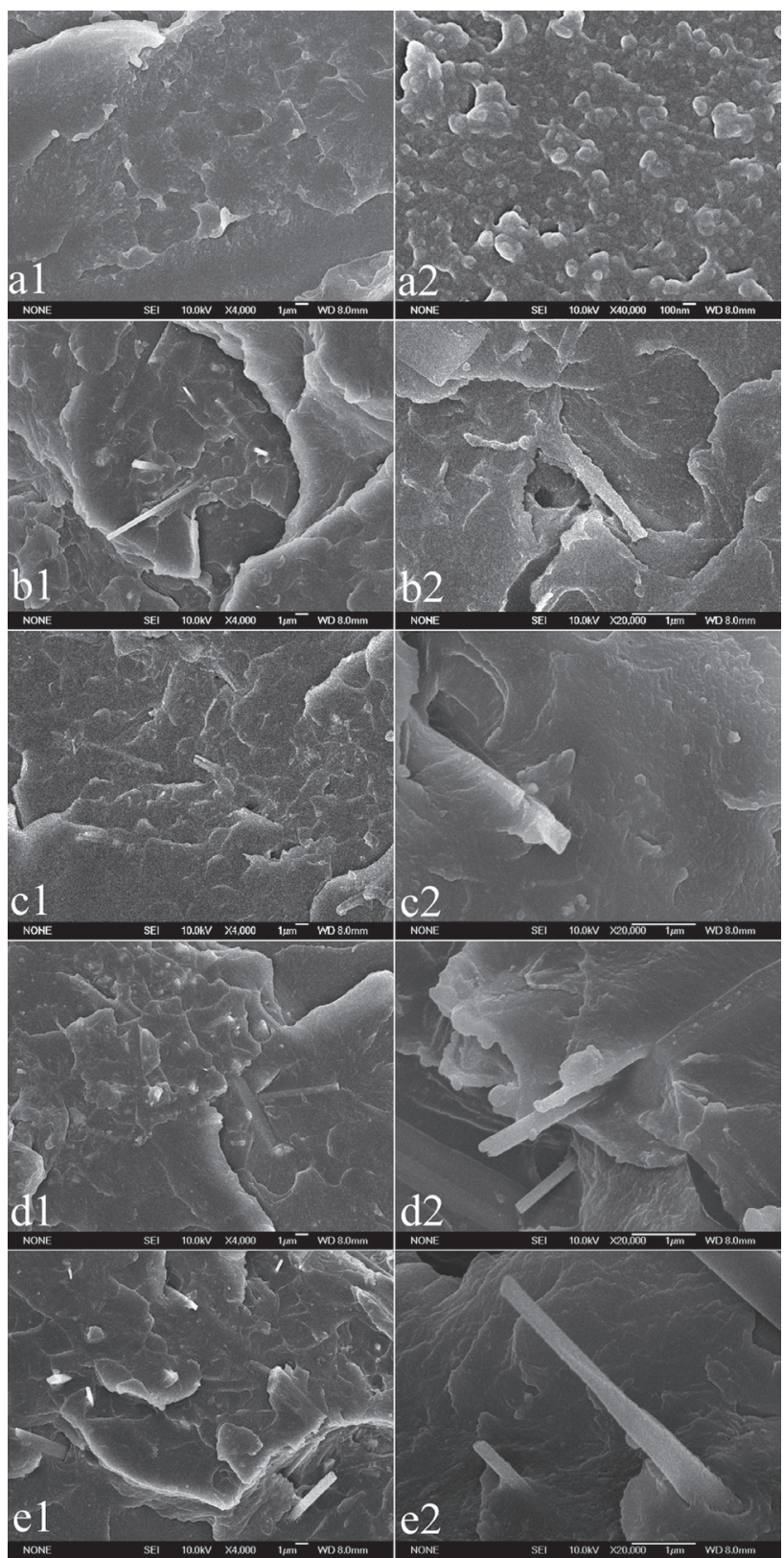

Fig. 2 SEM images of $\mathrm{ZrO}_{2}$-ABW/PMMA nanocomposites at different $\mathrm{ZrO}_{2} / \mathrm{ABW}$ ratios of: (a) $2: 1$ with $2 \%$ of nano- $\mathrm{ZrO}_{2}$; (b) $1: 1$ with $2 \%$ of nano- $\mathrm{ZrO}_{2}$; (c) $1: 2$ with $2 \%$ of nano- $\mathrm{ZrO}_{2}$; (d) $1: 3$ with $2 \%$ of nano- $\mathrm{ZrO}_{2}$; and (e) $1: 3$ with $4 \%$ of $\mathrm{ZrO}_{2}$. (1) Lower magnification at $\times 4,000$; (2) Higher magnification at $\times 20,000$.

nano- $\mathrm{ZrO}_{2}$ uniformly distributed in the matrix (Fig. $2(\mathrm{c} 1))$. The ABWs were impregnated with resin and well embedded in the resin matrix (Fig. 2(c2)).

When the filler content exceeded its optimal amount, entanglement and agglomeration of fillers occurred. In Fig. 2(d2), the smooth surfaces of ABWs and poor 
Table 2 Surface hardness of each group (The values with the same mark have no significant difference)

\begin{tabular}{cccc}
\hline \multicolumn{3}{c}{ Surface Hardness (MPa) } \\
\hline \multirow{3}{*}{$\mathrm{ZrO}_{2}$} & $\mathrm{ZrO}_{2} / \mathrm{ABW}$ & $\begin{array}{c}\text { Experimental } \\
\text { group }\end{array}$ & Control group \\
\hline & $2: 1$ & $18.5 \pm 0.6$ & $18.3 \pm 0.4$ \\
$1 \%$ & $1: 1$ & $19.5 \pm 1.1^{\mathrm{a}}$ & $18.4 \pm 0.3$ \\
& $1: 2$ & $18.8 \pm 1.0$ & $19.2 \pm 0.9^{\mathrm{a}}$ \\
& $1: 3$ & $18.4 \pm 0.6$ & $18.5 \pm 0.8$ \\
& $2: 1$ & $17.9 \pm 0.8$ & $18.4 \pm 0.6$ \\
$2 \%$ & $1: 1$ & $19.6 \pm 1.1^{\mathrm{a}}$ & $19.2 \pm 0.7^{\mathrm{a}}$ \\
& $1: 2$ & $21.8 \pm 1.3^{\mathrm{b}}$ & $19.6 \pm 1.1^{\mathrm{a}}$ \\
& $1: 3$ & $19.3 \pm 0.5^{\mathrm{a}}$ & $18.4 \pm 1.0$ \\
& $2: 1$ & $19.4 \pm 0.5^{\mathrm{a}}$ & $18.0 \pm 1.3$ \\
$3 \%$ & $1: 1$ & $21.2 \pm 0.4^{\mathrm{b}}$ & $18.6 \pm 0.9$ \\
& $1: 2$ & $22.5 \pm 0.9^{\mathrm{c}}$ & $20.1 \pm 1.1^{\mathrm{b}}$ \\
& $1: 3$ & $21.3 \pm 1.5^{\mathrm{b}}$ & $19.5 \pm 1.0^{\mathrm{a}}$ \\
& $2: 1$ & $19.5 \pm 0.6^{\mathrm{a}}$ & $18.0 \pm 0.7$ \\
$4 \%$ & $1: 1$ & $19.8 \pm 1.4^{\mathrm{b}}$ & $18.6 \pm 0.9$ \\
& $1: 2$ & $18.7 \pm 0.8$ & $19.2 \pm 1.2^{\mathrm{a}}$ \\
& $1: 3$ & $18.3 \pm 1.2$ & $18.5 \pm 1.5$
\end{tabular}

Blank group

(pure PMMA)

adhesion to the resin matrix were manifested. At $\mathrm{ZrO}_{2} /$ $\mathrm{ABW}$ ratio of $1: 3$ and nano- $\mathrm{ZrO}_{2}$ amount of $4 \%$, the fillers tended toward agglomeration, and the fracture surface demonstrated characteristics of brittle fracture at lower magnification (Fig. 2(e1)). At higher magnification, nano- $\mathrm{ZrO}_{2}$ and $\mathrm{ABWs}$ were unevenly dispersed in the matrix and gathered into clusters (Fig. 2(e2)).

\section{Surface hardness}

Silanized $\mathrm{ZrO}_{2}$-ABW/PMMA nanocomposites showed higher surface hardness than the control groups and the blank group (Table 2). The surface hardness of reinforced groups ran a similar changing pattern as flexural strength (Fig. 3). Silanized $\mathrm{ZrO}_{2}$-ABW/PMMA nanocomposites showed the highest surface hardness when amount of nano- $\mathrm{ZrO}_{2}$ was $3 \%$ (Fig. 3). It was significantly higher than the other groups $(p<0.001)$. At $3 \%$ of nano- $\mathrm{ZrO}_{2}$, surface hardness achieved the maximum value of $22.50 \pm 0.86 \mathrm{MPa}$ when $\mathrm{ZrO}_{2} / \mathrm{ABW}$ ratio was 1:2, which was significantly different from the other groups and the control group $(p<0.05)$. This was an increase of $27 \%$ when compared with the blank group (17.78 $\pm 0.50 \mathrm{MPa})$.

\section{DISCUSSION}

Many researches have shown that PMMA could be reinforced by the addition of rigid particles ${ }^{3,5,23,24)}$. The toughening effect of the particles has been explained in terms of certain fracture mechanisms, the most

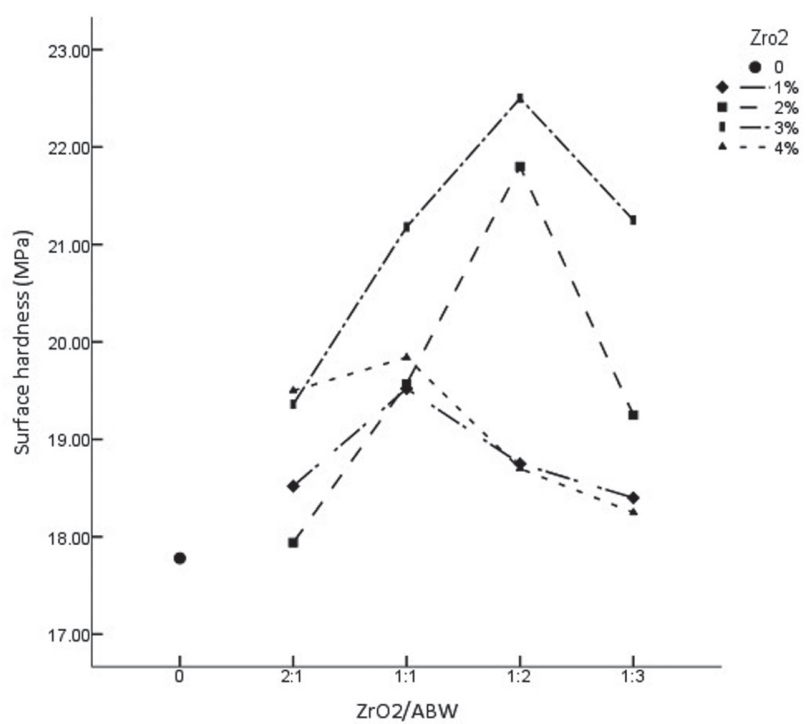

Fig. 3 Surface hardness values of silanized $\mathrm{ZrO}_{2}-\mathrm{ABW} /$ PMMA nanocomposites.

recognized being crack pinning, crack deflection, and plastic deformation ${ }^{23)}$. Although the existence of crack deflection and pinning was questioned, the definite improvement in mechanical properties of PMMA resins filled with nano- $\mathrm{ZrO}_{2}$ was unquestionable ${ }^{24)}$. In a previous study, the effects of nano- $\mathrm{ZrO}_{2}$ on the flexural strength and surface hardness of PMMA were evaluated ${ }^{25}$. Results showed that $\mathrm{ZrO}_{2} / \mathrm{PMMA}$ nanocomposites reached the highest flexural strength $(87.37 \pm 4.48 \mathrm{MPa})$ and surface hardness $(19.97 \pm 1.62$ $\mathrm{MPa}$ ) when nano- $\mathrm{ZrO}_{2}$ was added at $1.5 \mathrm{wt} \%$, which were increases of $23 \%$ and $12 \%$ when respectively compared with the pure PMMA. For ABWs, the toughening mechanisms included crack deflection, crack bridging, and frictional pullout ${ }^{26)}$. Our previous study ${ }^{18)}$ found that the flexural strength and surface hardness of PMMA resin reinforced with ABWs increased by $30 \%$.

In the present study, the flexural strength and surface hardness of silanized $\mathrm{ZrO}_{2}$-ABW/PMMA nanocomposites were raised by $52 \%$ and $27 \%$ respectively when compared with pure PMMA. The surface hardness of $\mathrm{ZrO}_{2}$-ABW/PMMA nanocomposites was not significantly different from that of $\mathrm{ABW} /$ PMMA nanocomposites ${ }^{18}$. However, the highest surface hardness value of ABW/PMMA nanocomposites was achieved at an $\mathrm{ABW}$ amount of $15 \%{ }^{18)}$, while $\mathrm{ZrO}_{2}$ - $\mathrm{ABW} /$ PMMA nanocomposites achieved the highest value at a ABW amount of $4 \%$ in the present study. Therefore, the reinforcing effect of $\mathrm{ZrO}_{2}$-ABW/PMMA nanocomposites was more effective, being more economical in the amount of fillers used. This was possible because of the synergistic effect of nano- $\mathrm{ZrO}_{2}$ and $\mathrm{ABWs}$ in enhancing the mechanical properties of PMMA. By compounding the two fillers together, nano- $\mathrm{ZrO}_{2}$ suppressed the grain growth of ABWs during polymerization. At the same 
time, ABWs acted as seeds for the grain growth of nano$\mathrm{ZrO}_{2}$ to form large elongated grains around the whiskers, thus resulting in a good grain mircostructure ${ }^{27-29)}$.

Due to the enormous specific surface area, high surface energy, and active chemical properties, nanoparticles have a strong tendency to aggregate and decrease particle-polymer interactions, thus lowering the reinforcement of PMMA ${ }^{9,30}$. In the present study, the strategy to modulate the dispersion of fillers and particle-polymer interactions was to surface-treat nano$\mathrm{ZrO}_{2}$ and $\mathrm{ABWs}$ with a silane coupling agent ( $\gamma$-MPTS). It is a bi-functional monomer, with the hydroxymethyl groups substituted by hydroxyl groups for attachment to the fillers. This decreased the surface tension of the particles and influenced the spatial distribution of fillers. On the other hand, $\gamma$-MPTS contained $\mathrm{C}=\mathrm{C}$ bonds which reacted with PMMA matrix during the curing process, thereby acting as a "molecular bridge" to establish chemical bonding between PMMA matrix and the particles. Silanized $\mathrm{ZrO}_{2}$-ABW/PMMA nanocomposites exhibited remarkably higher flexural strength and surface hardness than unsilanized nanocomposites in this study. Another way to control the dispersion of fillers and particle-polymer interactions was to manipulate the $\mathrm{ZrO}_{2}$-ABW/PMMA nanocomposites preparation procedure. Mechanical attrition, such as bead ball milling and ultrasonication, was used to temporarily resist the agglomeration tendency during the modification step.

Results of this study revealed that PMMA reinforcement was obviously related to the filler amount present in the composites, a claim substantiated by SEM images of their morphologies. The flexural strength and surface hardness of $\mathrm{ZrO}_{2}$-ABW/PMMA nanocomposites increased gradually at first. At this stage, SEM showed an increase in filler amount with homogeneous dispersion (Figs. 2(a) and (b)). At $\mathrm{ZrO}_{2} /$ $\mathrm{ABW}$ ratio of 1:2, $\mathrm{ABW}$ sere impregnated with resin and well embedded in the resin matrix, and nano- $\mathrm{ZrO}_{2}$ distributed evenly (Fig. 2(c)). At this ratio, highest mechanical properties were achieved. However, as the amount of fillers increased, the surfaces of ABWs remained clear and smooth with poor adhesion to the resin matrix, together with the emergence of clusters (Figs. 2(d) and (e)). As a result, the flexural strength and surface hardness deteriorated.

For denture base materials, flexural strength is of prime importance amongst a host of properties. For this reason, $2 \%$ of nano- $\mathrm{ZrO}_{2}$ at $\mathrm{ZrO}_{2} / \mathrm{ABW}$ ratio of $1: 2$ was determined as the optimum amount to reinforce $\mathrm{ZrO}_{2}$ ABW/PMMA nanocomposites so as to provide enhanced mechanical properties for removable partial dentures.

Besides mechanical properties, thermal property, dimension stability, and biocompatibility are also critical properties of a denture base material. More studies should be conducted to evaluate these properties to prove that $\mathrm{ZrO}_{2}$-ABW/PMMA nanocomposites are clinically satisfactory.

\section{CONCLUSIONS}

The amounts of nano- $\mathrm{ZrO}_{2}$ and $\mathrm{ABW}$ added to PMMA and their ratio significantly affected the flexural strength and surface hardness of $\mathrm{ZrO}_{2}$-ABW/PMMA nanocomposite material. To achieve maximum flexural strength, the optimum amount of nano- $\mathrm{ZrO}_{2}$ and $\mathrm{ABWs}$ to reinforce PMMA was $2 \%$ of nano- $\mathrm{ZrO}_{2}$ at $\mathrm{ZrO}_{2} / \mathrm{ABW}$ ratio of $1: 2$, causing flexural strength to increase by $52 \%$ when compared with pure PMMA. To achieve maximum surface hardness, the optimum amount was at $3 \%$ of nano- $\mathrm{ZrO}_{2}$ with the same $\mathrm{ZrO}_{2} / \mathrm{ABW}$ ratio, causing surface hardness to increase by $27 \%$ when compared with pure PMMA.

\section{REFERENCES}

1) Frankilin P, Wood DJ, Bubb NL. Reinforcement of poly (methyl methacrylate) denture base with glass flake. Dent Mater 2005; 21: 365-370.

2) Kanie T, Fujii K, Arikawa H, Inoue K. Flexural properties and impact strength of denture base polymer reinforced with woven glass fibers. Dent Mater 2000; 16: 150-158.

3) Qian C, Zhang XY, Zhu BS, Lin KL, Chang J, Zhang XJ. The effect of $\mathrm{CaSiO}_{3}$ nano-particles reinforced denture polymethyl methacrylate. Adv Compos Lett 2011; 20: 13-20.

4) Nakamura M, Takahashi H, Hayakawa I. Reinforcement of denture base resin with short-rod glass fiber. Dent Mater J 2007; 26: 733-738.

5) Atai M, Pahlavan A, Moin N. Nano-porous thermally sintered nano silica as novel fillers for dental composites. Dent Mater 2012; 28: 133-145.

6) Wang $Q Q$, Wang $X$, Li XJ, Cai YB, Wer QF. Surface modification of PMMA/O-MMT composite microfibers by $\mathrm{TiO}_{2}$ coating. Appl Surf Sci 2011; 258: 98-102.

7) Gao Y, Gao XP, Zhou YF, Yan DY. Preparation of poly (methyl methacrylate) grafted titanate nanotubes by in situ atom transfer radical polymerization. Nanotechnology 2008; 19: 495604 .

8) Xu HHK, Quinn JB, Giuseppetti AA, Eichmiller FC, Parry EE, Schumacher GE. Three-body wear of dental resin composites reinforced with silica-fused whiskers. Dent Mater 2004; 20: 220-227.

9) Jouault N, Dalmas F, Boue F, Jestin J. Multiscale characterization of filler dispersion and origins of mechanical reinforcement in model nanocomposites. Polymer 2012; 53: 761-775.

10) Sorrentino L, Berardini F, Capozzoli MR, Amitrano S, Iannace $\mathrm{S}$. Nano/micro ternary composites based on PP, nanoclay, and $\mathrm{CaCO}_{3}$. J Appl Polym Sci 2009; 113: 3360-3367.

11) Brown GM, Ellyin F. Mechanical properties and multiscale characterization of nanofiber-alumina/epoxy nanocomposites. J Appl Polym Sci 2011; 119: 1459-1468.

12) Luo ZX, Yang WS, Peng AD, Zeng Y, Yao JN. The fabrication of $\mathrm{TiO}_{2}$ nanorods from $\mathrm{TiO}_{2}$ nanoparticles by organic protection assisted template method. Nanotechnology 2009; 20: 345601 .

13) Wang XF, Huang ZM, Chen LS. Comparison study on transparent composites with different patterns of nanofiber reinforcement. Fiber Polym 2011; 12: 359-365.

14) $\mathrm{Mu}$ MF, Osswald S, Gogotsi Y, Winey KI. An in situ Raman spectroscopy study of stress transfer between carbon nanotubes and polymer. Nanotechnology 2009; 20: 335703.

15) Lin GM, Xie GY, Sui GX, Yang R. Hybrid effect of nanoparticles with carbon fibers on the mechanical and wear properties of polymer composite. Composites Part B: Engineering 2012; 43: 44-49. 
16) Koroglu A, Ozdemir T, Usanmaz A. Comparative study of the mechanical properties of fiber-reinforced denture base resin. J Appl Polym Sci 2009; 113: 716-720.

17) Shumsky VF, Getmanchuk IP, Lipatov YS. Effect of a filler on the rheological and mechanical properties of the liquidcrystalline polyester-poly(methyl methacrylate) blends. J Appl Polym Sci 2000; 76: 993-999.

18) Zhang XJ, Zhang XY, Zhu BS, Lin KL, Chang J. Mechanical and thermal properties of denture PMMA reinforced with silanized aluminum borate whiskers. Dent Mater J 2012; 31: 903-908.

19) Sung YM, Shin YK, Ryu JJ. Preparation of hydroxyapatite/ zirconia bioceramic nanocomposites for orthopaedic and dental prosthesis applications. Nanotechnology 2007; 18: 065602.

20) Ellakwa AE, Morsy MA, El-Sheikh AM. Effect of aluminum oxide addition on the flexural strength and thermal diffusivity of heat-polymerized acrylic resin. J Prosthodont 2008; 17: 439-444.

21) Pallav P, De Gee AJ, Davidson CL, Erickson RL, Glasspoole EA. The influence of admixing microfiller to small-particle composite resin on wear, tensile strength, hardness, and surface roughness. J Dent Res 1989; 68: 489-490.

22) ISO 20795-1:2008. Dentistry -Base polymer- Part 1: Denture base polymers.

23) Medina R, Haupert F, Schlarb AK. Improvement of tensile properties and toughness of an epoxy resin by nanozirconium- dioxide reinforcement. J Mater Sci 2008; 43: 3245-3252.

24) Alhareb $\mathrm{AO}$, Ahmad ZA. Effect of $\mathrm{Al}_{2} \mathrm{O}_{3} / \mathrm{ZrO}_{2}$ hybrid on the fracture toughness and flexural properties of PMMA denture base. Adv Mater Res 2011; 173: 18-23.

25) Zhang XJ, Zhang XY, Zhu BS, Qian C. Effect of nano $\mathrm{ZrO} 2$ on flexural strength and surface hardness of polymethylmethacrylate. Shanghai Kou Qiang Yi Xue 2011; 20: 358-363.

26) Bengisu M, Inal OT. Whisker toughening of ceramics: toughening mechanisms, fabrication, and composite properties. Annu Rev Mater Sci 1994; 24: 83-124.

27) Koh YH, Kim HW, Kim HE. Mechanical properties and oxidation resistance of $\mathrm{Si}_{3} \mathrm{~N}_{4}-\mathrm{SiC}$ nanocomposites. Scripta Mater 2001; 44: 2069-2073.

28) Xu HHK, Sun L, Weir MD, Takagi SK, Chow LC, Hockey B Effects of incorporating nanosized calcium phosphate particles on properties of whisker-reinforced dental composites. J Biomed Mater Res Part B (Appl Biomater) 2007; 81: 116125.

29) Koh YH, Kim HW, Kim HE. Microstructural evolution and mechanical properties of $\mathrm{Si}_{3} \mathrm{~N}_{4}-\mathrm{SiC}$ (nanoparticle)- $\mathrm{Si}_{3} \mathrm{~N}_{4}$ (whisker) composites. J Mater Res 2000; 15: 364-368.

30) Qu M, Meth JS, Blackman GS, Cohen GM, Sharp KG, Van Vliet KJ. Tailoring and probing particle-polymer interactions in PMMA/silica nanocomposites. Soft Matter 2011; 7: 84018408. 